Session 1566

\title{
Knowledge Bowl for Manufacturing Processes
}

\author{
YeutSheng Paul Shiue \\ Mechanical Engineering Department \\ Christian Brothers University \\ Memphis, TN 38104 \\ USA
}

\begin{abstract}
The Manufacturing Processes (ME 201) class in the Mechanical Engineering (ME) Department at Christian Brothers University (CBU) is a required course for all ME students. This class combines traditional machining, advanced machining $(\mathrm{CNC})$, and rapid prototyping techniques with field trips and hands-on projects. One of the highlights of this class is the manufacturing bowl at the end of the semester. Students are divided into four groups to compete in the knowledge of manufacturing. The winning group is selected by means of the double-elimination process. A gaming device that consists of a console and two push-button control boxes is created for the competition. Seven sets of multiple-choice questions are created in PowerPoint presentations. Prior to the end of the semester, a final project is assigned to have each group of students design their own trophy for the competition. This project illustrates students' creativity, their ability to work as a team and their manufacturing skills.
\end{abstract}

The competition serves as a review of materials covered in the class. It boosts up the interest and motivation of students in the area of manufacturing processes.

\section{Introduction}

The interactive approach in teaching and learning has been an effective methodology for all levels of classroom instruction. It enlightens the traditional lecture style while building up students' interest in the subject throughout the semester. The Manufacturing Processes (ME201) class in the Department of Mechanical Engineering (ME) at Christian Brothers University (CBU) is a required course for all ME students. This class includes four parts: concepts and theory, field trips, hands-on projects, and knowledge bowl. In the concepts and theory portion, different manufacturing processes and material properties are introduced. Students learn to use different kinds of traditional machining tools such as lathes, mills, drills, bend saws, power shear, and other power tools. Welding devices such as oxyfuel torch, MIG, TIG, SMAW and plasma cutter, 
are also a part of practice projects. In the second half of the semester, rapid prototyping and CNC machining are introduced to students as well as NC programming and robotic assembly. Students learn to write NC code manually and machine parts on the CNC machine. In addition, approximately five field trips to local companies are arranged. Students learn from engineers in industry and actually visualize their manufacturing processes. Projects corresponding to course material utilize machine tools in the MEDevelopment Shop at CBU. The capabilities of Pro/ENGINEER ${ }^{\circledR}$ are also introduced with NC programming. The highlight of the class is the Manufacturing Bowl at the end of the semester. Students are divided into four groups for competition in general knowledge in manufacturing. The competition is conducted with multimedia presentation using Microsoft PowerPoint. The gaming devices consist of a console

and two push-button devices. A total of 7 sets of questions with 15 questions in each set were developed using PowerPoint presentation. The competition adopts the rule of double elimination. Along with the competition, each group will design and manufacture its own trophy as a final project. The competition brings the excitement of learning manufacturing processes to students while the final trophy project focuses on the creativity, manufacturability, and workmanship.

\section{Competition Structure and Rules}

The manufacturing bowl is intended to be a friendly competition between classmates on their general knowledge of manufacturing processes. Topics include basic manufacturing processes, properties of materials, heat treatment, destructive and nondestructive testing, chip-type machining, cutting tools, welding, CNC machining, and last, but not least, rapid prototyping technologies. Questions are given in the form of multiple choice and designed to be answered within 5 seconds. Calculations are almost nonexistent or so trivial that a calculator is not needed. Seven sets of questions with a total of 105 questions are developed using Microsoft ${ }^{\circledR}$ PowerPoint $^{\circledR}$ including vocal instructions. Figure 1 shows some example slides of the competition.

Each team consists of four to five members depending on the size of the class. A total of four teams will be formed prior to the competition. The same team will work as a group for their final trophy project. Each team will compete against each other by blind draw at the beginning. The sequence of competition is similar to the double elimination tournament. The winning team in each round will be named EAGLE and the losing team will be named BIRD. Figure 2 shows the sequence of the competition. In the championship game, IRON EAGLE will have to beat SILVER EAGLE twice to be the champion of the match.

General rules of the competition are as follows:

- Most points, not most correct answers, determine the winner;

- Teams may discuss their answer;

- Absolutely no talking in the audience during the competition;

- Teams must be on time and ready to start;

- Teams cannot switch members;

- Timing continues during contestant responses;

- Timing stops during any deliberations by the device control personnel or instructor;

Proceedings of the 2004 American Society for Engineering Education Annual Conference \& Exposition Copyright (C) 2004, American Society for Engineering Education 
- Tie breaker - Team with most correct answers;

- The textbook, "Materials and Processes in Manufacturing" by DeGarmo ${ }^{1}$ is allowed for reference.

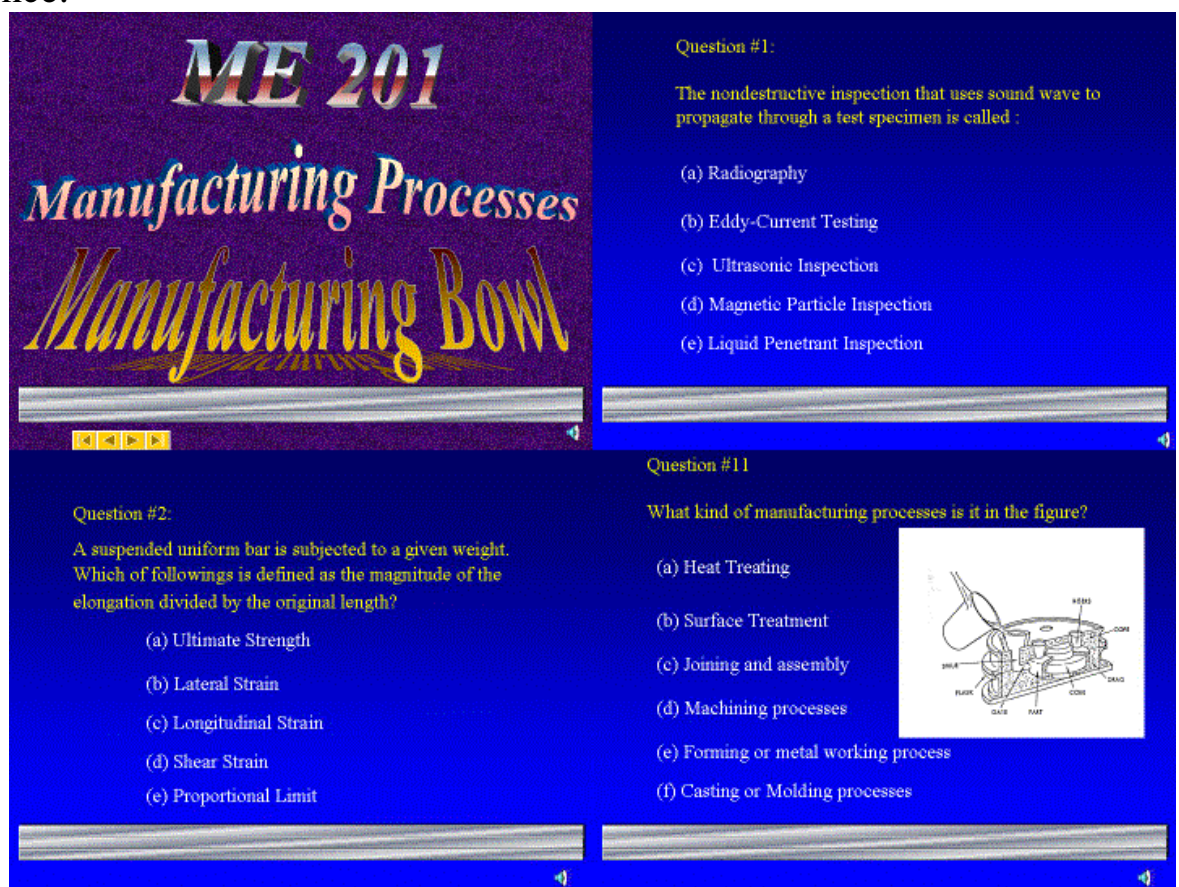

Figure 1: Example slides of the competition

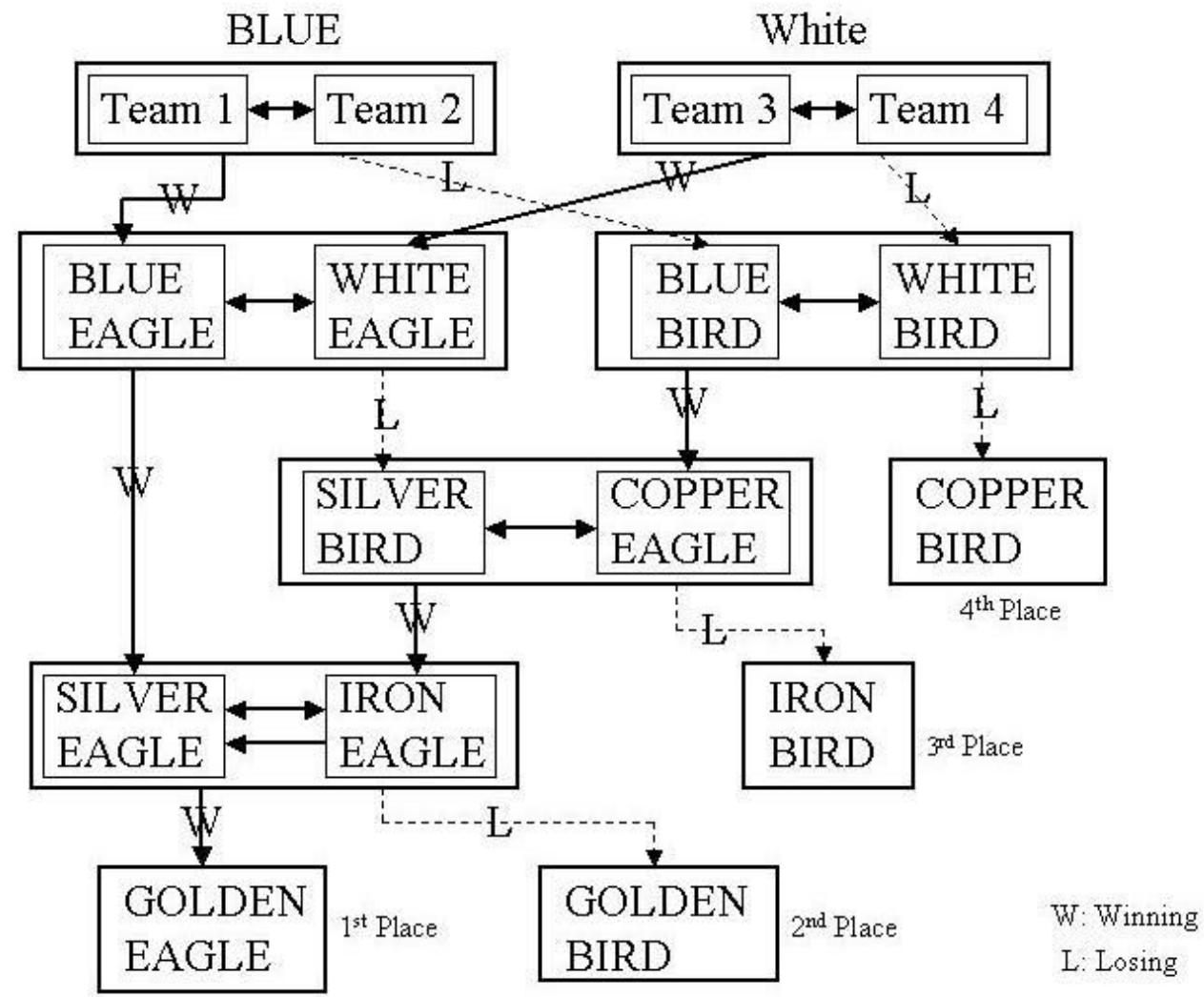

Figure 2: Sequence of the Competition 
There are 15 questions in each round. Any team member may answer the question any time during the announcement of the question. However, each team has only one chance to answer the question. Points awarded are based on following guidelines:

- Hit the answer button and get the correct answer before the announcement of the question -40 points;

- Hit the answer button and get the correct answer during the announcement of multiple choices - 20 points;

- Hit the answer button and get the correct answer after all the multiple choices are announced - 10 points;

- If no one answers the question in ten seconds after the multiple choices are announced, the question will be skipped.

\section{The Gaming Device}

The gaming devices consist of one console and two push-button controllers. On the console, there are two light-indicators, BLUE and RED, and one RESET button. On each controller, there are one light indicator and one ANSWER button. The circuit is designed to accept the first team who hits the button. Once the first team hits the button and the light-indicators are on, the other controller will not take effect anymore until the RESET button is pressed to clear the lightindicators. Four AA batteries are used to power the devices. Two miniature PC board relays (American Zettler, AZ8-1CH-5DE) are used for the control. All connections are shown in Figure 3.

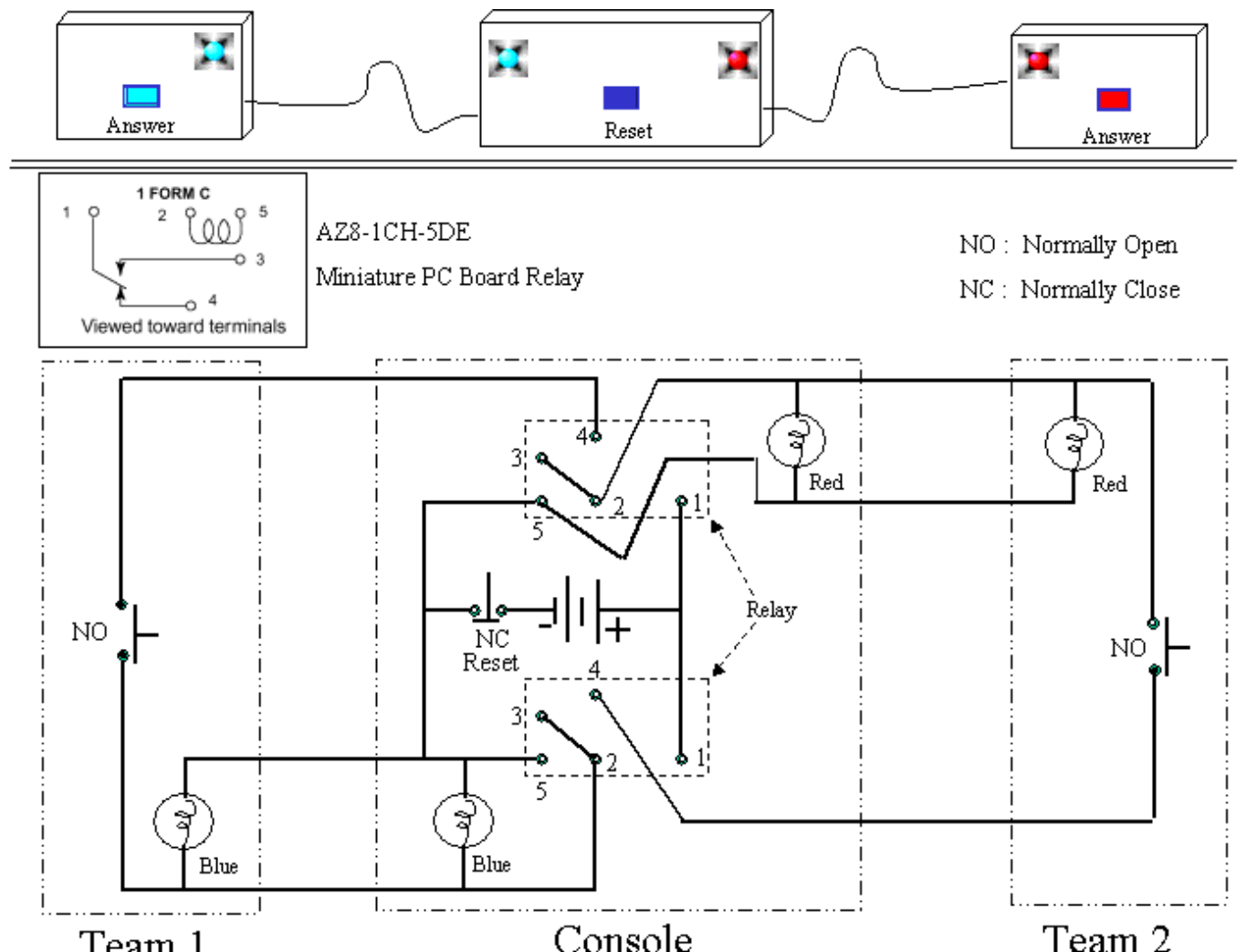

Team 1

Console

Team 2

Figure 3: Connections of the Gaming Devices

Proceedings of the 2004 American Society for Engineering Education Annual Conference \& Exposition Copyright (C) 2004, American Society for Engineering Education 


\section{The Trophy Project}

Along with the competition, each group will design their trophy as their final project. Three other faculty members are invited to be judges of the project. Figure 4 shows some of the trophies. Grading of the trophy project is based on the following four items:

(1) Design and modeling (40\%) - In this category, the design ideas, Pro/ENGINEER models and assemblies are evaluated for innovation, accuracy, and completeness.

(2) Manufacturing Difficulty (30\%) - The complexity of the part and machining involved are evaluated in this category. Students are encouraged to use all machining tools available in the ME Development Shop.

(3) Appearance (20\%) - In this category, the appearance of the trophy is evaluated.

(4) Teamwork (10\%) - Each group will submit a work distribution sheet for the project.
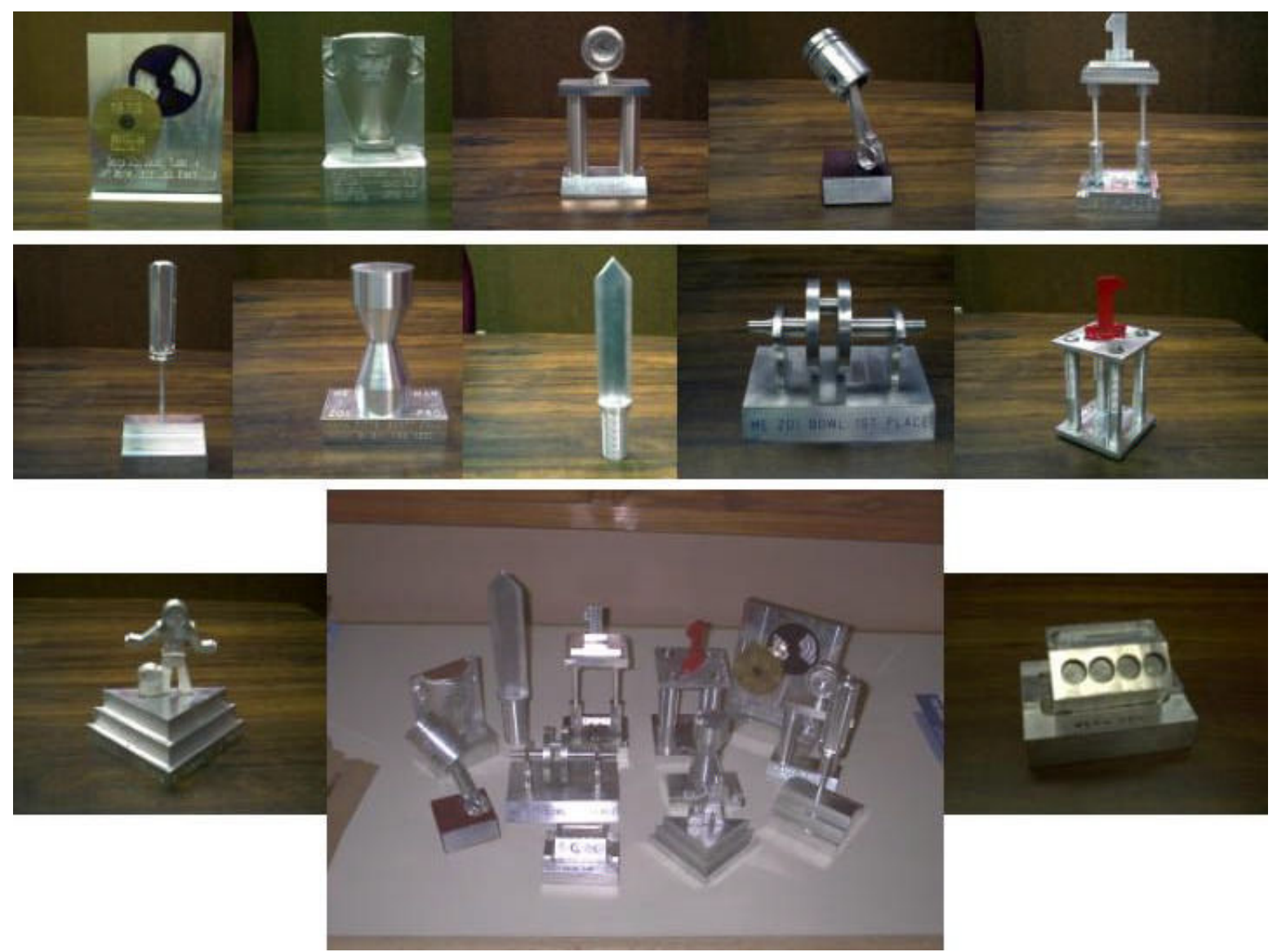

Figure 4: Trophies for the Competition.

\section{Summary}

The Manufacturing Bowl serves as a review of all materials covered in the class. Compared to traditional classroom instruction, it contributes to the excitement in the class. This interactive exercise provides students with a fun and challenging environment to learn manufacturing 
processes. The final trophy project gives students the opportunity to optimize their creativity as well as their drafting and manufacturing skills. This exercise can be adopted not only for manufacturing processes but also for other areas of classroom activities. Different subjects of competitions can use the same gaming devices. The devices are easy to make which ensures fairness in the competition.

The success of the competition and the trophy project was revealed in the student evaluations and the final exam at the end of semester. All manufacturing skills become the backbone of other class projects and senior project especially the moonbuggy construction for the Great Moonbuggy Race hosted by NASA in April every year.

There are still some improvements to be made. For example: create a database for different subjects of questions; use Microsoft Visual Basic to develop interface to select question sets and perform the competition; design a gaming device that uses a parallel port of the computer to automatically control the answering sequence. This is an ongoing project that will make classroom instruction more effective, fun, and challenging.

\section{References}

1. DeGarmo, E.P., et. al., Materials and Processes in Manufacturing, 9th Edition, Macmillan, 2003

\section{Biography}

YEU-SHENG PAUL SHIUE, a Professor at Christian Brothers University, received his B.S. from Tatung University in Taiwan and his M.S. and Ph.D. degrees from the University of Memphis in Memphis, TN. He is an associate member of the American Society of Mechanical Engineers and a professional member of American Society for Engineering Education. Currently, he is focusing on concurrent engineering and intermediate manufacturing processes utilizing Pro/ENGINEER ${ }^{\circledR}, \mathrm{CNC}$ machining centers, and rapid prototyping. 